\title{
Technology and research-based strategies: learning and alternative conceptions
}

\author{
Mónica Quezada-Espinoza ${ }^{1}$, Valeria del Campo ${ }^{2}$, Genaro Zavala ${ }^{1,3}$ \\ ${ }^{I}$ Physics Education Research and Innovation Group, Tecnológico de Monterrey, Monterrey, Mexico \\ ${ }^{2}$ Physics Department, Universidad Técnica Federico Santa Maria, Valparaiso, Chile \\ ${ }^{3}$ Engineering School, Universidad Andres Bello, Santiago, Chile
}

\begin{abstract}
Several educational strategies and tools have been designed to improve physics education for undergraduate students. Physics Education Technology (PhET) is a recent technology based on interactive simulations that provides the possibility to experiment real world phenomena without the need for laboratory equipment. Similarly, Tutorials for Introductory Physics have been proved to be one of the best research-based strategies to promote conceptual understanding. We worked in a Chilean private university with engineering students who were not familiar with PhET simulations but somewhat with Tutorials. We examined students' conceptual learning of electric circuit concepts after they worked on two Tutorials with a PhET simulation instead of real equipment. We report results of their learning from pre/post-tests and an openended test- We note the benefits of using technology combined with research-based strategies in positively influencing students learning.
\end{abstract}

Keywords: PhET simulations, Tutorials, Use of technology, Active Learning, Students' conceptions.

PACS: 01.40.Fk, 01.40.gb, 01.50.H

\section{INTRODUCTION}

The use of research-based strategies and technology for teaching physical concepts has been a topic in Physics Education Research (PER) for some years $[1,2]$. However, there are many universities that have not experienced this type of interactive engagement activities. We conducted this research at a Chilean university in which active learning activities had already been implemented in the first two introductory physics courses. The present study was carried out in the third course, Electricity and Magnetism (E\&M), in which active learning activities had not been implemented before. The majority of students took the Mechanics course using SCALE-UP rooms [3] with some Tutorials [4], Interactive Learning Demonstrations [5] and Problem-solving activities. However, in the E\&M course, this was the first time in which Tutorials and other active learning activities were introduced.

One of the very common problems to implement direct current (DC) Tutorials, is that bulbs and batteries are needed. In Chile it was impossible to find identical small bulbs for the activities. Instead of looking at this situation as a shortcoming, we decided to use PhET sims [6], an experience that other groups had implemented before [7,8]. We believed that this would be a valuable experience for students since they had not used the PhET sims before, and we would have the opportunity to reach a better understanding of the use of technology in active learning. Many reports show that students have serious difficulties learning E\&M concepts, especially current, resistance and voltage $[9,10,11]$, because they have strong alternative conceptions. We wanted to see if this combination of strategies was successful to overcome those conceptions.

We conducted this research by implementing two electric circuit Tutorials [4] using PhET sims [6] (Circuit Construction Kit-DC) following the Framework for Simulation Use in Educational Settings [12]. The objective was to assess students' conceptual learning and alternative conceptions after use of a research-based simulation with a research-based strategy for the first time in this university.

\section{METHODOLOGY}

This investigation involved 60 students enrolled in an introductory $\mathrm{E} \& \mathrm{M}$ course for engineering. The course's format is a semester with two 90-min. lectures and one 90-min. small-group recitation session per week. Also, students spend two hours every two weeks in a physics laboratory.

\section{A. Activities}

We used two DC circuits Tutorials in an environment of a SCALE-UP type room: one that focuses on the concept of current and another that focuses on the concept of potential difference [4] using PhET sims instead of bulbs and batteries. We were careful to follow a framework [12] in which the simulation was PhET; the environment was mainly the room and the assignment consisted on the Tutorials. Activities were guided by an instructor previously trained for this type of active learning instruction. 


\section{B. Pre/Post-test}

We used 14 items from the Determining and Interpreting Resistive Electric Circuit Concepts Test version 1.2 (DIRECT), that evaluates students' understanding of DC circuit concepts [10], to measure students' learning from the start (pre) to the end (post) of two activities based on the use of Tutorials with PhET sims. The chosen items are focused on current, voltage and circuits configuration. These items were retrieved in Spanish from a previous publication [13]. We used part of the DIRECT to evaluate only the topics that were addressed in the activities. We calculated the normalized gain $\langle\mathrm{g}\rangle$ [14]. Out of 60 students that participated in this study, 48 of them took both the pre and the post-test.

\section{Open-ended test}

We decided to test, in much greater detail, students' understanding of the concepts of a complete circuit focusing on the concept of current. Therefore, based on a series of alternative conceptions reported in the literature [15], we designed a problem of six open qualitative questions to be part of an evaluation administered to students one week after the activities. The alternative conceptions reported by Peşman and Eryllmaz, which were classified as conceptual models, are: (1) the sink model, (2) the attenuation model, (3) the shared current model, (4) the sequential model, (5) the clashing current model (6), the empirical rule model, (7) the short-circuit model, (8) the power supply as constant-current source model, (9) the parallel circuit model, and (10) the local reasoning model.

We focused on the conceptions in italics: the sequential model, in which it is assumed that a change at a point in an electrical circuit affects the circuit forward in the direction of the current, not backward; the short-circuit model, in which a wire without electrical devices connected is ignored when analyzing an electrical circuit; the power supply as constant-current source model, in which any power supply is thought to provide a constant current to a circuit; and the local reasoning model, in which in case of a change in a circuit, students focus on local changes instead of a global analysis. The design and analysis of open-ended test were based on those conceptions. This test was administered to 56 students after the activities with Tutorials and PhET sims.

\section{RESULTS AND DISCUSSION}

\section{A. Gain}

The gain calculated for the group $(n=48)$, who completed pre and post-test, was of $\langle\mathrm{g}\rangle=0.41$, a medium gain according to Hake's classification for mechanics [14]. We calculated gains for each item in the pre/post-test and observed that 4 out of 14 items had a high-gain level, 6 had a medium-gain level, and 4 had a low-gain level. Items in the high-gain level were related to ranking voltages in a series circuit with two bulbs, comparing current in two points of a circuit with one bulb, identifying arrays of a circuit which lights a bulb, and identifying changes in a series circuit when resistance increases. In contrast, low-level gains items were related to the effect of extra wires in a circuit and the link between real circuit representations with symbolic representation. This last result is in agreement with what another similar study has reported [8].

\section{B. Analysis of conceptions from the open-ended test}

In this paper, we report on the analysis of three out of six qualitative open-ended questions. In the first part of the problem students were asked to rank the currents of the bulbs which is not analyzed here. Figure 1 presents the second part, in this part students were asked to respond what happens with the current in bulb $\mathrm{D}$ when a wire is connected between points 1 and 2. Note that students are told that the bulbs are identical, and the wires are ideal.

Now, an ideal wire is connected between points 1 and 2 as shown in Circuit 2 . Considering the new wire connected, is the current through bulb D in Circuit 2 greater than, less than or the same as the current through bulb D in Circuit 1 ? Explain clearly your reasoning.
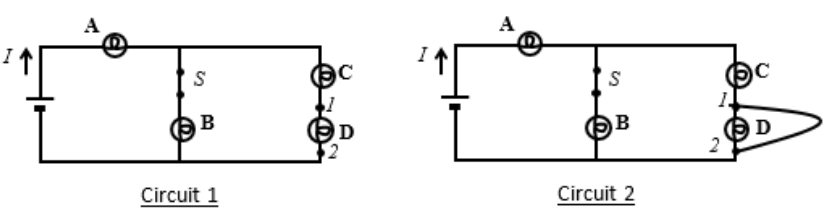

FIG 1. The short-circuit question of the open-ended test.

This question was designed based on the shortcircuit conception. In this alternative conception, students underestimate the wire effects on the circuit because it does not have an electrical device connected. Table 1 shows the main results of students' responses. 
TABLE 1. Results for the short-circuit question.

\begin{tabular}{c|l}
\hline $\begin{array}{l}\text { Responses } \\
\text { (\#students) }\end{array}$ & \multicolumn{1}{c}{ Reasoning (\#students) } \\
\hline $\begin{array}{c}\text { Current now is zero } \\
(22)\end{array}$ & $\begin{array}{l}\text { - Current takes the path of less } \\
\text { resistance (12) } \\
\text { - Potential difference is zero (6) } \\
\text { - There is a short circuit (3) } \\
\text { - Other (1) }\end{array}$ \\
\hline $\begin{array}{c}\text { Current is non-zero } \\
\text { and less than before } \\
(23)\end{array}$ & $\begin{array}{l}\text { - Current divides between the bulb and } \\
\text { the wire (23) }\end{array}$ \\
\hline $\begin{array}{c}\text { The current is the } \\
\text { same as before (14) }\end{array}$ & $\begin{array}{l}\text { - Resistance is zero so current is too (7) } \\
\text { (5) Wire has no electric devices connected } \\
- \text { Current through the wire is zero (2) }\end{array}$ \\
\hline
\end{tabular}

22 students $(37 \%)$ responded correctly, i.e., current is zero and students gave different reasoning for this response. On the other hand, 23 students (39\%) believed that the current is less because it is divided between the bulb and the wire, which is partially correct; however, since the wire was ideal, all the current goes through it. Finally, fourteen students (24\%) answered using the short-circuit conception; mostly they ignored the wire giving three different reasoning that are typical for this conception [15].

Analyzing further this alternative conception, we found that answers in both pre-posttest and openended test are consistent. Two of the items used from DIRECT were designed based and the short circuit alternative conception [10]. Figure 2 shows the diagrams for these two questions. (a)
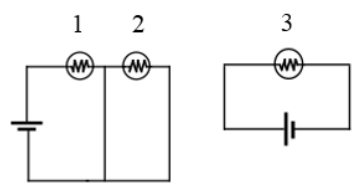

(b)

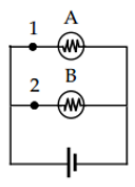

FIG 2. In (a), the item asks to compare brightness between the bulbs 1,2 and 3. The item in (b) asks what happens to the brightness of bulbs $\mathrm{A}$ and $\mathrm{B}$ when a wire is connected between points 1 and 2 .

For (a) $60 \%$ of students responded the right answer (bulbs 1 and 3 are equally bright), but an important portion $(27 \%)$ of students said that bulb 3 was brighter. It means that those students take into account the connected wire despite the fact that it does not have an electric device ignoring that this is an ideal wire with zero resistance. The number of right answers does not change between pre and posttest.

In (b) $67 \%$ of students answer correctly (they stay the same), but there was a portion of students $(25 \%)$ who answer that neither bulb will light. In the DC Tutorials the short circuit concept is not treated directly, this concept is intended to be an indirect learning from the circuits' models. The current and resistance Tutorial use bulbs with the same resistance in all activities and establishes a model for current distribution in series and parallel circuits. In the potential difference Tutorial the case of elements with different resistance is presented and the relationship between potential differences and brightness is established. This final model enables the students to compare currents and potential differences between different loops of the circuit. The case of the shortcut circuit can be seen as the limit case of two parallel resistances. Therefore, the students are expected to relate the potential difference model with our open ended question.

Continuing the analysis of open-ended test, fig. 3 shows the next two questions. In these questions, students were asked to explain what happens to the current through c) the battery and through d) bulb A, when the switch is opened.

Returning to original Circuit 1, we open the switch (S) as in figure shown below in Circuit 3. Based on this modification, answer questions c) and d).

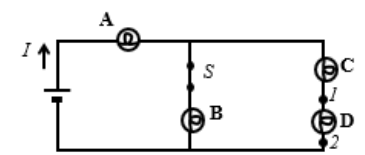

Circuit 1

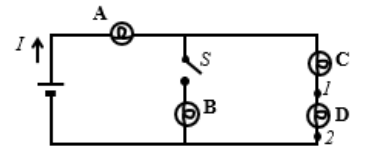

$\underline{\text { Circuit } 3}$ c) Is the current through the battery in Circuit 3 greater than, less than or the same as the current through the battery in Circuit 1 ? Explain clearly your reasoning.

d) Is the current through bulb A in Circuit 3 greater than, less than or the same as the current through bulb $\mathrm{A}$ in Circuit 1 ? Explain clearly your reasoning.

FIG 3. The switch model questions of the open-ended test.

Table 2 shows the results for question c) and Table 3 the results for question d) from fig. 2 .

TABLE 2. Responses and reasoning for question c) of the problem (how is the current through the battery when the switch is opened).

\begin{tabular}{l|l}
\hline \multicolumn{1}{c|}{$\begin{array}{c}\text { Responses } \\
\text { (\#students) }\end{array}$} & \multicolumn{1}{c}{ Conceptions (\#students) } \\
\hline $\begin{array}{l}\text { Now the current } \\
\text { through the battery is } \\
\text { less than before (36) }\end{array}$ & $\begin{array}{l}\text { - When } \mathrm{S} \text { is opened, } \mathrm{R}_{\mathrm{eq}} \text { increases, so } \\
\text { the current decreases }(36)\end{array}$ \\
\hline $\begin{array}{l}\text { The current through } \\
\text { the battery is the } \\
\text { same }(20)\end{array}$ & $\begin{array}{l}\text { - Local reasoning (12) } \\
\text { - Power supply as constant-current } \\
\text { source }(8)\end{array}$ \\
\hline
\end{tabular}

36 students (64\%) answered this question correctly with adequate reasoning, a main objective of the first Tutorial (A model for circuits Part 1). However, 20 students $(36 \%)$ answered that the current through the battery is the same: 8 students had the conception of the battery as a constant-current source and explicitly stated that the current through the battery does not change because now the current is not divided; 12 students had a local reasoning model, they focus on local changes in the circuit instead of a global analysis of it. 
TABLE 3. Responses and reasoning for question d) of the problem (how is the current through the bulb A, when the switch is opened).

\begin{tabular}{c|l}
\hline Responses (\#students) & Conceptions (\#students) \\
\hline $\begin{array}{c}\text { Current through bulb A } \\
\text { is now less (32) }\end{array}$ & $\begin{array}{l}\text { - Current in the battery is the } \\
\text { same as the current through } \\
\text { bulb A (32) }\end{array}$ \\
\hline $\begin{array}{c}\text { Current through bulb A } \\
\text { is the same (21) }\end{array}$ & $\begin{array}{l}\text { - Local reasoning (16) } \\
\text { - Sequential (3) } \\
\text { - Other (2) }\end{array}$ \\
\hline
\end{tabular}

32 students (61\%) answered this question correctly. $21(39 \%)$ students answered that the current through bulb $\mathrm{A}$ is the same. From those, 16 students had a local conception and 3 of them a sequential conception.

Analyzing questions from Fig. 3 together, we found some interesting results. In general the students who had a local model answering question c), also had a local model when answering question $\mathrm{d}$ ); they were consistent. Another consistency we found is that all students who had a sequential model in d), had the conception of a battery as a constant-current source model in c). It seems that these two models are connected. However, those students who had the battery as a constant-current source model in c), were divided into various reasoning when answering $d$ ). It seems that the connection between the sequential model and the constant-current source model is only in one direction.

[1] J. M. Fraser, J. M., A. L. Timan, K. Miller, J. E. Dowd, L. Tucker, and E. Mazur, E. Reports on Progress in Physics, 77(3), (2014).

[2] Z. A. C. Krusberg, J. Sci. Educ. Technol., 16, 5, (2007).

[3] R. J. Beichner, J. M. Saul, D. S. Abbott, J. J. Morse, L. Duane, R. J. Allain, and J. S. Risley in Research Based Reform of University Physics, edited by E. F. Redish and P. J. Cooney, (2007).

[4] L. C. McDermott, P. S. Shaffer, and the Physics Education Group, Tutorials in Introductory Physics (Prentice-Hall, Englewood Cliffs, NJ, 1998).

[5] D. R. Sokoloff \& R. K, Thornton. (1997). Phys. Teach., 35(6), 340, (1997).

[6] C. E. Wieman, W. K. Adams, W. K., and K. K. Perkins, Science, 322, 5902 (2008).

[7] N. Finkelstein, W. Adams, C. Keller, K. Perkins, and C. Wieman, JOLT, 2, 3, (2006).

[8] G. Zavala, and J. J. Velarde, Proceedings of X Congreso Nacional de Investigación Educativa, 7, 1-13, (2009).

[9] M. Baser, J. Sci. Educ. Technol., 15, 5. (2006).

\section{CONCLUSIONS}

The objective for this study was to assess students' conceptual learning and alternative conceptions after use of a research-based simulation with a researchbased strategy for the first time in this university. The three elements in our implementation were: the environment element, which consisted of the SCALEUP-type classroom, the collaborative instructors and the resources such as computers; the simulation element, the PhET; and the assignment element, the adaptation of a much known research-based strategy, the Tutorials. It was found that this combination following the three essential elements of the Framework for Simulation Use in Educational Settings [12] resulted in an activity for students' understanding electric circuits. However, some students kept alternative conceptions reported in the literature, which we believe is due in part to the fact that this is the first time we implemented Tutorials and PhET sims. We found that there could be a connection among conceptions; a further analysis of these conceptions and their relation to the use of PhET sims will be reported in the future. The results of this implementation have implications for instruction. Considering there will be a time in which bulbs will be difficult to find, the Tutorials can still be used successfully using PhET sims.

[10] P. V. Engelhardt, and R.J. Beichner, Am. J. Phys., 72, 1 (2004).

[11] M. R. Stetzer, P. van Kampen, P. S. Shaffer, P. S., and L. C. McDermott, Am. J. Phys., 81, 2, (2013).

[12] D. A. Rehn, E. B. Moore, N. S. Podolefsky and N. D. Finkelstein, JoTLT, 2, 1, (2013).

[13] M. Quezada-Espinoza and G. Zavala, LAJPE, 8, 4, (2014).

[14] R. R. Hake, Am. J. Phys., 66, 1, (1998).

[15] H. Peşman and A. Eryılmaz, J. Ed. Res., 103, 3, (2010). 